\title{
O Princípio da Prevenção sob o Enfoque Ambiental e da Saúde: um Imperativo Sociodemocrático
}

\section{LEANDRO PEIXOTO MEDEIROS}

Membro do Núcleo de Estudos em Ciências Criminais (NECC) e do Centro de Estudos em Direito Constitucional (CEDIC) da Universidade Federal do Ceará.

Submissão: 06.02 .2013

Decisão Editorial: 11.04 .2013

RESUMO: 0 presente artigo desenvolve estudo acerca do princípio da prevenção, desvendando as suas nuances tanto à luz do Direito Ambiental como sob o enfoque da saúde. A pós-modernidade fez surgir novos desafios à humanidade, repercutindo na defesa de suas maiores prerrogativas, as quais se encontram alicerçadas no texto constitucional. A tutela de direitos coletivos é face de um novo momento do Estado, ao qual se incumbe, juntamente com a coletividade, a proteção de novos direitos, incidentes na esfera jurídica de toda a sociedade, constituídos sob a égide da Lei Maior. Compreender o princípio da prevenção em mais de uma perspectiva leva a uma superação conceitual, imputando-Ihe as vestes de imperativo sociodemocrático. Com supedâneo na doutrina mais abalizada e na jurisprudência pertinente ao tema, a pesquisa intenta desfazer falsas perspectivas e edificar novos parâmetros de efetivação do princípio em tela, tanto no campo ambiental como no da saúde.

PALAVRAS-CHAVE: Princípio da prevenção; direito ambiental; saúde.

ABSTRACT: The present article develops a study about the principle of prevention, discovering its nuances with focus on the environmental law and on the health. The post-modernity made come out new challenges to humanity, affecting on the defense of their major prerogatives, found on the constitutional text. The collective rights is part of a new moment of the state, which is responsible, along with the collective, for the protection of new rights, appearing on the juridical area of whole society, composed under the aegis of the Constitution. To understand the principle of prevention on more the one perspective takes to a conceptual overcoming, giving the title of a socio-democratic imperative. With basis on the best doctrine and on case law about the subject, the research seeks to undo fake perspectives and to construct new parameters of implementation of the principle on focus, on the environmental field and on the health.

KEYWORDS: Principle of prevention; environmental law; health.

SUMÁRIO: Introdução; 1 A prevenção como princípio; 2 A natureza jurídica do direito ao meio ambiente sadio; 30 princípio da prevenção à luz do Direito Ambiental; 3.1 Prevenção x precaução: a segurança científica como pressuposto; 3.1.1 Princípio da precaução; 3.1.2 Princípio da prevenção: a ciência aliada à proteção ambiental; 40 princípio da prevenção sob o enfoque da saúde; 4.10 direito social à saúde e as atividades preventivas; 4.2 A prevenção como instrumento de efetivação da saúde; 5 A prevenção como imperativo sociodemocrático do meio ambiente e da saúde; Conclusão; Referências. 


\section{INTRODUÇÃOO}

A mudança de épocas dita novas perspectivas, traçadas a partir de parâmetros distintos e fundadas sob a égide dos anseios sociais reinantes a cada tempo. O Direito, por sua autêntica natureza cambiante, acompanha a mutabilidade do homem ao disciplinar novos institutos e a exigir dele novas condutas. Neste sentido, afirma Pontes de Miranda que "o Direito não é outra coisa que processo de adaptação" 1 .

Deste modo, a cada momento histórico vigoram necessidades diferentes, compatíveis com o contexto social com o qual se deparam. Tais necessidades encontram na ciência jurídica a sua principal ferramenta de defesa e continuidade. Destarte, é a Constituição Federal de 1988, na qualidade de Lex Fundamentalis do Estado, que assegura a proteção dos direitos do homem, a exemplo do direito ao meio ambiente ecologicamente equilibrado ${ }^{2}$ e do direito à saúde 3 .

O crescimento do setor produtivo trouxe consigo desafios inerentes à pós-modernidade, a exemplo da compatibilização do desenvolvimento econômico e social com a preservação dos recursos naturais. A defesa do meio ambiente tornou-se aspecto crítico do atual estágio social da humanidade, sobrelevando-se como uma necessidade ímpar.

No esteio de José Afonso da Silva, "o problema da tutela jurídica do meio ambiente manifesta-se a partir do momento em que sua degradação passa a ameaçar não só o bem-estar, mas a qualidade de vida humana, se não a própria sobrevivência do ser humano" ${ }^{\prime 4}$.

Da mesma forma, a saúde, como direito de todos, é outro ponto nevrálgico das dificuldades enfrentadas pelo homem, estando fortemente relacionada com a própria proteção ao meio ambiente.

Neste jaez, faz-se mister compreender o papel norteador da prevenção no ordenamento jurídico, partindo-se de sua estrutura principiológica, a fim de que se possa revelar o encargo decisivo que assume na condução de um meio ambiente ecologicamente equilibrado e de uma saúde efetiva a todos.

\section{A PREVENÇÃO COMO PRINCÍPIO}

Os princípios são normas aptas a orientar todo um complexo de relações jurídicas, apresentando caráter de fundamentalidade. A prevenção revela a sua

Pontes de Miranda, 1967, p. 31.

CF/1988, art. 225: "Todos têm direito ao meio ambiente ecologicamente equilibrado, bem de uso comum do povo e essencial à sadia qualidade de vida, impondo-se ao Poder Público e à coletividade o dever de defendêlo e preservá-lo para as presentes e futuras gerações".

3 CF/1988, art. 196: "A saúde é direito de todos e dever do Estado, garantido mediante políticas sociais e econômicas que visem à redução do risco de doença e de outros agravos e ao acesso universal e igualitário às ações e serviços para sua promoção, proteção e recuperação".

4 José Afonso da Silva, 2000, p. 28. 
natureza principiológica a partir do momento em que se torna diretriz do ordenamento jurídico, capaz de guiar e influenciar uma série de comportamentos e ações.

No escólio de Celso Antônio Bandeira de Mello, princípio é o

mandamento nuclear de um sistema, verdadeiro alicerce dele, disposição fundamental que se irradia sobre diferentes normas compondo-lhes o espírito e servindo de critério para sua exata compreensão e inteligência, exatamente por definir a lógica e a racionalidade do sistema normativo, no que lhe confere a tônica e Ihe dá sentido harmônico. ${ }^{5}$

Estruturalmente, manifesta-se a natureza dos princípios no fato de admitirem ou postularem concretizações, densificações, realizações variáveis. Por outro lado, deve o operador jurídico levá-los em conta, tomando-os como firmes pontos de referência, interpretando-os segundo os critérios próprios da hermenêutica jurídica e dando-Ihes, por conseguinte, o devido cumprimento ${ }^{6}$.

Ademais, Robert Alexy, a seu turno, fortifica o debate ao ponderar acerca da natureza dos princípios, asseverando que são

normas que ordenam que algo seja realizado na maior medida possível dentro das possibilidades jurídicas e fáticas existentes. Princípios são, por conseguinte, mandamentos de otimização, que são caracterizados por poderem ser satisfeitos em graus variados e pelo fato de que a medida devida de sua satisfação não depende somente das possibilidades fáticas, mas também das possibilidades jurídicas. ${ }^{7}$

Portanto, à medida que se pugna prioritariamente por ações que evitem a ocorrência de eventos danosos, a prevenção edifica-se estruturalmente como um princípio, ou seja, como um padrão "juridicamente vinculante radicado nas exigências de 'justiça' (Dworkin) ou na 'ideia de direito' (Larenz)"8, a servir de referência e a direcionar as bases de políticas ambientais e de saúde.

\section{A NATUREZA JURÍDICA DO DIREITO AO MEIO AMBIENTE SADIO}

O direito ao meio ambiente ecologicamente equilibrado é constitucionalmente assegurado a todos (art. 225 da CF/1988), independentemente de nacionalidade, raça, sexo, idade ou condição social. A todos interessa a preservação do meio ambiente saudável, valor intimamente ligado ao direito à vida. Logo, o direito à integridade do meio ambiente constitui uma prerrogativa jurídica de titularidade coletiva, e não individual ${ }^{9}$.

Mello, 1996, p. 545-546.

Jorge Miranda, 1996, p. 226.

Alexy, 2008, p. 90-91.

Canotilho, 1999, p. 1124.

Neste sentido: "A questão do Direito ao meio ambiente ecologicamente equilibrado [...] constitui prerrogativa jurídica de titularidade coletiva, refletindo, dentro do processo de afirmação dos direitos humanos, a expressão 
Sendo assim, o direito ao meio ambiente sadio consubstancia a "proteção de direitos pluri-individuais que superam as noções tradicionais de interesse individual ou coletivo"10, classificando-se como um direito difuso.

A Lei no 8.078/1.990, em seu art. 81, parágrafo único, I, trouxe um conceito legal de direito difuso, ao afirmá-lo como um direito transindividual, "de natureza indivisível, de que sejam titulares pessoas indeterminadas e ligadas por circunstâncias de fato".

Portanto, consoante aponta Romeu Thomé, "o interesse ao meio ambiente saudável, em regra, é classificado como difuso em decorrência de sua natureza indivisível, bem como por envolver segmentos indeterminados da sociedade"11. A sua indivisibilidade manifesta-se na impossibilidade de cindi-lo, de modo que um típico exemplo é o próprio ar atmosférico ${ }^{12}$. Já a indeterminação de seus titulares emana da dificuldade de determiná-los, mesmo estando interligados por circunstâncias de fato.

A importância de sua natureza jurídica mostra-se ainda mais proeminente quando, por exemplo, o Superior Tribunal de Justiça decidiu, em 2009, pela imprescritibilidade do direito à reparação do dano ambiental, entendendo que

no conflito entre estabelecer um prazo prescricional em favor do causador do dano ambiental, a fim de Ihe atribuir segurança jurídica e estabilidade com natureza eminentemente privada, e tutelar de forma mais benéfica bem jurídico coletivo, indisponível, fundamental, que antecede todos os demais direitos - pois sem ele não há vida, nem saúde, nem trabalho, nem lazer - o último prevalece, por óbvio, concluindo pela imprescritibilidade do direito à reparação do dano ambiental. ${ }^{13}$

Por fim, cumpre lembrar a tradicional classificação dos direitos fundamentais em gerações ou dimensões, na qual o direito ao meio ambiente encontra-se catalogado como direito de terceira geração ou dimensão.

Tais direitos possuem como grande destinatário o gênero humano ${ }^{14} \mathrm{e}$ notabilizam-se pela titularidade difusa ou coletiva, haja vista serem concebidos para a proteção não do homem individualizado, mas de coletividades.

Ademais, são também chamados de direitos de fraternidade ou solidariedade, dotados de considerável carga de humanismo e universalidade. Além do

significativa de um poder atribuído, não ao indivíduo identificado em sua singularidade, mas, num sentido verdadeiramente mais abrangente, a própria coletividade social" (STF, MS 22.164/SP, T.P., Rel. Min. Celso de Mello, DJU 17.11.1995).

10 Mukai, 1998, p. 6.

11 Thomé, 2011, p. 114

12 Fiorillo, 2010, p. 55.

13 REsp 1.120.117/AC, Rel ${ }^{a}$ Min. Eliana Calmon, J. 10.11.2009; Informativo n 415 do STJ.

14 Bonavides, 2008, p. 259. 
direito à qualidade do meio ambiente, são exemplos o direito à paz, ao desenvolvimento e à conservação do patrimônio histórico e cultural.

\section{PRINCÍPIO DA PREVENÇ̃̃O À LUZ DO DIREITO AMBIENTAL}

O princípio da prevenção afigura-se como um dos mais cruciais princípios do direito ambiental, balizando toda a aplicação legislativa tendente a efetivar a proteção do meio ambiente.

Os danos ambientais, por sua natureza e na grande maioria dos casos, são irreparáveis ou de difícil reparação. O retorno ao status quo ante de um ecossistema é tarefa árdua, quando não impossível. Não se podem mensurar os prejuízos da extinção de uma espécie, da desertificação de áreas produtivas, ou da destruição de uma floresta repleta de ecossistemas plurais ${ }^{15}$.

Neste trilhar, a fim de que melhor se conceitue dano ambiental, José Rubens Morato Leite e Patryck de Araújo Ayala prelecionam que este consiste, em uma primeira acepção, em uma indesejável alteração ao conjunto de elementos chamados meio ambiente. Configura-se, portanto, na lesão ao direito fundamental que todos possuem de gozar e valer-se do meio ambiente equilibrado. Já em uma segunda acepção, o dano engloba os efeitos que tal modificação gera na saúde das pessoas e em seus interesses ${ }^{16}$.

Desta forma, é inegável a necessidade da adoção de todas as medidas possíveis e aptas a prevenir a ocorrência do dano ambiental ou a minimizar os seus efeitos.

No atual estágio produtivo industrial, em que existem múltiplas formas de agressão ao meio ambiente, evidenciam-se necessárias todas as ações que se antecipem aos eventos lesivos, que evitem a degradação ambiental.

Nas palavras de Cristiane Derani, o referido princípio

indica uma atuação "racional" para com os bens ambientais, com a mais cuidadosa apreensão possível dos recursos naturais, numa espécie de Daseinvorsorge ou Zukiunftvorsorge (cuidado, precaução com a existência ou com o futuro), que vai além de simples medidas para afastar o perigo. Na verdade, é uma "precaução contra o risco", que objetiva prevenir já uma suspeição de perigo. Seu trabalho está anterior à manifestação do perigo. ${ }^{17}$

15 Neste sentido, Marta Carolina Fahel Lôbo: "As agressões ao meio ambiente, quando consumadas, demonstramse normalmente dificultosas e de impossível reparação, pois uma vez atingido determinado meio, por mais que se tente restabelecer o status quo ante, este não o será em sua origem, o que acarretará, em verdade, uma amenização das consequências. Isto gera a ideia de reparação incerta e em regra custosa, pois despendese com estudos complexos, que envolvem os mais variados estudiosos como químicos, biólogos, geólogos, geógrafos, físicos, economistas, advogados, entre outros" (2005, p. 13).

16 Leite; Ayala, 2011, p. 94.

17 Derani, 1997, p. 165. 
Deste modo, constitui-se a prevenção como a própria essência do direito do ambiente, a sua verdadeira direção e norte, a indicar os caminhos do alcance de seu objetivo fundamental.

A propósito, a Constituição Federal de 1988 adotou o princípio da prevenção, ao preceituar, no caput do art. 225, o dever do Poder Público e da coletividade de proteger e preservar o meio ambiente para as presentes e futuras gerações, conforme se pode perceber, verbo ad verbum:

Art. 225. Todos têm direito ao meio ambiente ecologicamente equilibrado, bem de uso comum do povo e essencial à sadia qualidade de vida, impondo-se ao Poder Público e à coletividade o dever de defendê-lo e preservá-lo para as presentes e futuras gerações.

Ora, a defesa e a preservação do meio ambiente passam, por corolário lógico, pelas ações e medidas que visem a afastar o risco de resultados lesivos, que previnam a ocorrência de eventos danosos capazes de prejudicar o meio ambiente equilibrado, bem de titularidade difusa.

O melhor caminho para a efetivação de tal defesa, indubitavelmente, passa por um processo de conscientização, a incutir nas mentes da população a verdadeira necessidade de preservar aquilo que está intimamente relacionado com a sua própria subsistência: o bem ambiental. Entretanto, como mostra Celso Antonio Pacheco Fiorillo, não pode nem deve o Direito esperar de braços cruzados o advento de tal conscientização:

A prevenção e a preservação devem ser concretizadas por meio de uma consciência ecológica, a qual deve ser desenvolvida através de uma política de educação ambiental. De fato, é a consciência ecológica que propiciará o sucesso no combate preventivo do dano ambiental. Todavia, deve-se ter em vista que a nossa realidade ainda não contempla aludida consciência, de modo que outros instrumentos tornam-se relevantes na realização do princípio da prevenção. Para tanto observamos instrumentos como o estudo prévio de impacto ambiental (EIA/RIMA), o manejo ecológico, o tombamento, as liminares, as sanções administrativas etc. ${ }^{18}$

Portanto, não podem a sociedade e o Estado contentarem-se em reparar e reprimir o dano ambiental. Urge ser feita atuação preventiva mediante a utilização de instrumentos que antecipem a sua ocorrência.

Neste diapasão, Édis Millaré ressalta a assertiva, costumeiramente repetida, de que os objetivos do direito ambiental são fundamentalmente preventivos, afirmando que a sua atenção volta-se para o momento anterior ao da consumação do dano, o momento do mero risco. Logo, tendo em vista a pouca valia 
da reparação, naturalmente incerta e, quando possível, extremamente onerosa, revela-se a prevenção como a melhor, quando não a única, solução ${ }^{19}$.

\subsection{Prevenção X Precaução: a SeGurança CIENTífica COMO PRESSUPOSTO}

Prevenção, no que concerne à sua origem etimológica, é substantivo do verbo prevenir (do latim prae $=$ antes e venire $=$ chegar, vir), e significa o ato ou o efeito de antecipar-se, chegar primeiro; demonstra uma conotação de generalidade, antecipação no tempo com intuito conhecido. Já precaução é substantivo do verbo precaver-se (do latim prae $=$ antes e cavere $=$ tomar cuidado), e recomenda cuidados antecipados com o que não se conhece, cautela para que uma ação não venha a produzir efeitos indesejáveis ${ }^{20}$.

\subsubsection{Princípio da precaução}

Segundo Paulo de Bessa Antunes, o princípio da precaução encontra sua gênese no Direito alemão, a partir da década de 1970. Em sua formulação original, ele estabelecia o desenvolvimento, em todos os setores da economia, de processos que reduzissem significativamente as cargas ambientais, principalmente as oriundas de substâncias perigosas ${ }^{21}$.

Com a evolução temporal, tal princípio tem sido utilizado quando se pretende evitar o mínimo risco ao meio ambiente, notadamente nos casos de incerteza científica acerca de sua degradação. Deste modo, quando existir dúvida sobre a potencialidade da lesão ao meio ambiente no que diz respeito a qualquer conduta que se pretenda incorrer, incide o princípio da precaução para prevenir o meio ambiente de um risco futuro ${ }^{22}$.

Com isso, o princípio da precaução apresenta um grande diferencial relativamente ao princípio da prevenção: a ausência de certeza científica quanto à extensão do dano ambiental. Ele enuncia todas as ações tendentes à proteção do meio ambiente, notadamente nos casos em que reina a dúvida científica no que concerne à real lesividade das condutas.

Desta feita, o princípio da precaução implica dizer que não somos apenas responsáveis pelo que nós sabemos, pelo que nós deveríamos ter sabido, mas, também, pelo que nós deveríamos duvidar ${ }^{23}$.

Foi assim que, na Conferência do Rio 92, foi proposto formalmente o princípio da precaução, estampado no princípio quinze da Declaração do Rio 92. É o que se pode constatar, ipsis litteris:

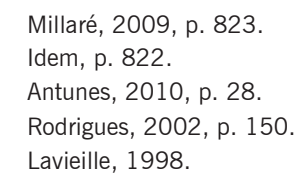


Princípio quinze da Declaração do Rio sobre Meio Ambiente e Desenvolvimento - Com o fim de proteger o meio ambiente, o princípio da precaução deverá ser amplamente observado pelos Estados, de acordo com suas capacidades. Quando houver ameaça de danos graves ou irreversíveis, a ausência de certeza científica absoluta não será utilizada como razão para o adiamento de medidas economicamente viáveis para prevenir a degradação ambiental. ${ }^{24}$

A mero título exemplificativo, o consumo dos alimentos transgênicos ou alimentos geneticamente modificados, atividade com efeitos pouco conhecidos pelo ser humano, revela campo fértil à incidência da precaução, na medida em que não se tem completa convicção do que deles pode advir.

Ademais, conforme preconiza Romeu Thomé, também não se deve raciocinar em vias absolutas, visto que "a aplicação do princípio da precaução deve ainda limitar-se aos casos de riscos graves e irreversíveis, e não a riscos de qualquer natureza", a fim de que não se inviabilize o próprio desenvolvimento científico e econômico ${ }^{25}$.

A defesa do meio ambiente saudável, prerrogativa jurídica de titularidade coletiva, requer medidas efetivas, de modo a evitar a degradação ambiental. Tais medidas são orientadas também pela precaução, já reconhecida judicialmente ${ }^{26-27}$, fornecendo substrato ao brocardo in dubio pro salute ou in dubio pro natura, o qual disserta que, na dúvida, deve-se dar preferência à solução que proteja imediatamente o ser humano e conserve o meio ambiente ${ }^{28}$.

\subsubsection{Princípio da prevenção: a ciência aliada à proteção ambiental}

A evolução dos estudos científicos é o grande pilar do ser humano, capaz de edificar a sua sobrevivência. A ciência permite conhecer o que antes se temia, desmentir falsas percepções, além de orientar caminhos que auxiliem o homem em sua jornada. Conhecer é de inequívoca importância para que as populações consigam se desenvolver plenamente, em todas as suas vertentes.

24 Brasil, 2012.

25 Thomé, op. cit., p. 70

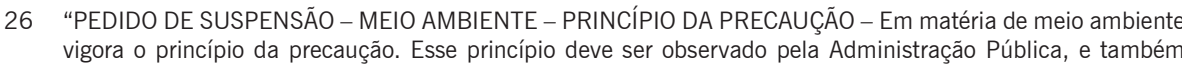
pelos empreendedores. A segurança dos investimentos constitui, também e principalmente, responsabilidade de quem os faz. [...]" (STJ, AgRg-SL-SS 1.564, (2012/0079795-7), C.Esp., Rel. Min. Ari Pargendler, DJe 06.06.2012, p. 289)

27 “AÇÃO CIVIL PÚBLICA - ANTECIPAÇÃO DE TUTELA - INSTALAÇ̃̃O DE ANTENA DE TELEFONIA MÓVEL - COMPETÊNCIA DA JUSTIÇA ESTADUAL - DISSENSO NA LITERATURA MÉDICA - RISCOS PARA SAÚDE HUMANA - PRINCÍPIO DA PRECAUÇÃO - REQUISITOS PRESENTES - As questões atinentes ao meio ambiente sadio e ao direito à saúde não estão suscetíveis de serem expostas a qualquer tipo de risco, sendo certo que presente dissenso na literatura médica quanto aos possíveis efeitos maléficos da radiação não ionizante, advinda das antenas de telefonia móvel, mesmo quando obedecidos os limites impostos pela Anatel, à luz do Princípio da Precaução, deve ser deferida a medida antecipatória, para paralisação da sua instalação." (TJMG, Al 1.0718.07.001441-7/001, Rel. Nilo Lacerda, DJ 14.08.2008)

28 Machado, 2010, p. 83. 
Desta forma, conhecer os impactos ambientais de uma atividade concede arrimo para que se constate a sua real valia tanto econômica quanto socialmente. O conhecimento permite que se melhor valore os prós e os contras de determinada empreitada e, caso se constate a sua agressividade ao meio ambiente, que se a impeça de prosperar.

Assim sendo, o princípio da prevenção, por sua vez, se apoia na certeza científica do impacto ambiental de determinada atividade. Ele determina justamente que, com base no que a ciência afirma ser lesivo, se pratiquem todas as medidas hábeis a prevenir a ocorrência do dano ambiental.

A atividade pretoriana já demonstrou a relevância do tema, conforme se percebe do preciso posicionamento infracolacionado do Tribunal de Justiça do Rio Grande do Sul:

Agravo de instrumento. Direito ambiental. Princípio da prevenção. No plano do direito ambiental vige o princípio da prevenção, que deve atuar como balizador de qualquer política moderna do meio ambiente. As medidas que evitam o nascimento de atentados ao meio ambiente devem ser priorizadas. $\mathrm{Na}$ atual conjuntura jurídica o princípio do interesse e bens coletivos predominam sobre o interesse particular ou privado. $\mathrm{O}$ argumento de que a concessão de medida liminar pode dar ensejo à falência não serve como substrato à continuidade de atos lesivos ao meio ambiente. ${ }^{29}$

Portanto, diante do exposto, é possível estabelecer uma nítida diferença entre o princípio da prevenção e o princípio da precaução. Enquanto a prevenção é efetivada quando são cediços os prejuízos provocados ao meio ambiente decorrentes da atividade potencialmente predadora ou poluidora, mediante a presença de elementos seguros para afirmar a sua periculosidade, a precaução ocorre quando não se conhece de fato o impacto da ação potencialmente degradadora, o que dá ensejo à imposição de restrições ou impedimentos à intervenção no meio ambiente até que se comprove que ela não acarreta efeitos adversos a ele ${ }^{30}$.

\section{PRINCÍPIO DA PREVENÇÃO SOB O ENFOQUE DA SAÚDE}

\subsection{DIREITO SOCIAL À SAÚDE E AS ATIVIDADES PREVENTIVAS}

O direito à saúde é constitucionalmente assegurado como um direito social ${ }^{31}$, sendo a sua defesa de competência legislativa concorrente dos entes fe-

29 TJRS, Al 597204262, Rel. Des. Arno Werlang, J. 05.08.1998.

30 Thomé, op. cit., p. 71.

31 "Art. $6^{\circ}$ São direitos sociais a educação, a saúde, a alimentação, o trabalho, a moradia, o lazer, a segurança, a previdência social, a proteção à maternidade e à infância, a assistência aos desamparados, na forma desta Constituição." 
derados $^{32}$. Em seu Título VIII, Capítulo II, Seção II, a Constituição Federal dispõe as normas gerais da saúde, inclusive do seu sistema único (SUS).

Neste sentido, o art. 196 da Constituição Federal de 1988 afirma a saúde como um "direito de todos e dever do Estado, garantido mediante políticas sociais e econômicas que visem à redução do risco de doença e de outros agravos e ao acesso universal e igualitário às ações e serviços para sua promoção, proteção e recuperação".

Ademais, o texto constitucional, visando à execução das políticas públicas de saúde, instituiu o Sistema Único de Saúde (SUS), organizado a partir do atendimento integral, com prioridade para as atividades preventivas, entre outras diretrizes (art. 198, II, da CF/1988). Tais atividades são privilegiadas também em sede infraconstitucional, conforme o art. 5으, III, da Lei no 8.080/1990, o qual define como um dos objetivos do SUS "a assistência às pessoas por intermédio de ações de promoção, proteção e recuperação da saúde, com a realização integrada das ações assistenciais e das atividades preventivas".

\subsection{A PREVENÇ̃̃o COMO INSTRUMENTO de EFETIVação da SAÚdE}

A concepção de saúde assume, nos dias atuais, três vertentes: ações de promoção da saúde, prevenção das doenças e o seu tratamento.

Desta forma, a promoção diz respeito aos determinantes das condições de saúde. Estas se referem à qualidade de vida, alimentação, nutrição, educação, habitação, saneamento, lazer, além de uma gama adequada de cuidados de saúde. Trata-se, portanto, de uma promoção da saúde centrada no indivíduo, projetando-se para a família e para a sociedade. Constitui-se na expressão maior da educação em saúde ${ }^{33}$.

A seu turno, a prevenção assume papel de notável relevância. Naturalmente, impedir que um mal se efetive deve ser objetivo primordial de qualquer sistema ou política de saúde, seja por impedir o advento do fato danoso e as suas consequências à saúde, seja por onerar menos em função de um eventual tratamento.

As ações preventivas apresentam-se como intervenções orientadas a evitar o surgimento de doenças específicas, mitigando a sua incidência e prevalência nas populações. Deste modo, a prevenção em saúde "exige uma ação antecipada, baseada no conhecimento da história natural a fim de tornar improvável o progresso posterior da doença" ${ }^{\prime \prime 4}$.

32 "Art. 24. Compete à União, aos Estados e ao Distrito Federal legislar concorrentemente sobre: [...] XII - previdência social, proteção e defesa da saúde; [...]"

33 Netto, 2011

34 Leavell; Clarck, 1976, p. 17. 
A fundamentação do princípio da prevenção na área da saúde encontra arrimo no conhecimento epidemiológico moderno, tendo por objetivo o controle da transmissão de doenças infecciosas e a redução do risco de doenças degenerativas ou outros agravos específicos ${ }^{35}$.

Neste diapasão, a prevenção indica o dever do Estado de antecipar-se às situações de fato para que não haja a deterioração da saúde diante de seus tutelados ${ }^{36}$.

Por fim, cabe trazer à baila a concepção de direitos sociais de José Afonso da Silva, para quem tais direitos "são prestações positivas, enunciadas em normas constitucionais, que possibilitam melhores condições de vida aos mais fracos ${ }^{\prime \prime 3}$. O princípio da prevenção atua na saúde justamente como uma das faces dessas prestações positivas, corroborando para o fortalecimento da dignidade da pessoa humana.

\section{A PREVENÇÃO COMO IMPERATIVO SOCIODEMOCRÁTICO DO MEIO AMBIENTE E DA SAÚDE}

A pós-modernidade trouxe consigo uma série de mudanças no desenvolvimento das sociedades, construindo novos estilos de vida e fazendo nascer novas necessidades. $\mathrm{O}$ homem passou a enfrentar dificuldades que antes não enfrentava, a conviver com um contexto que exige dele uma real adaptação.

O meio ambiente, conceito que transpassa o individual, alcançando toda a coletividade que dele necessita, foi, durante muito tempo, deixado em segundo plano, por força dos meios e das técnicas de produção que pouco atentavam para a sua preservação.

Consequentemente, os recursos naturais não suportaram a desenfreada noção de progresso que perdurou ao longo do século XIX e de parte do século $X X$, impulsionado a todo custo e a todo vapor.

A água, em diversas localidades, tornou-se escassa e até mesmo contaminada. Do mesmo modo, viu-se considerável aumento da temperatura média terrestre, ao que se deu a alcunha de aquecimento global, alterando o clima do planeta. A perda da biodiversidade, pautada na extinção de inúmeras espécies animais e vegetais, apenas representa mais uma vertente do que se pode, de fato, chamar de crise ambiental ${ }^{38}$.

5 Czeresnia, 1999, p. 4.

36 Elias, 2008.

37 José Afonso da Silva, op. cit., p. 258.

38 Neste sentido, Édis Millaré: "Por isso, é pacificamente aceito em nossos dias que preservar e restabelecer o equilíbrio ecológico é questão de vida ou morte. Os riscos globais, a extinção de espécies animais e vegetais, assim como a satisfação de novas necessidades em termos de qualidade de vida, deixam claro que o fenômeno biológico e suas manifestações sobre o Planeta estão perigosamente alterados" (2009, p. 785). 
Tal crise ensejou a solidificação daquilo que José Adércio Leite Sampaio denominou de prima principium do Direito Ambiental ${ }^{39}$, qual seja o desenvolvimento sustentável, conceito ajustado na harmonização de três fatores: crescimento econômico, preservação ambiental e equidade social.

Paralelamente, no campo da saúde, o crescimento populacional, as aludidas mudanças climáticas, as condições de vida degradantes em diversas partes do mundo, o manejo de elementos potencialmente lesivos à integridade corporal, além de outros fatores de influência, fizeram eclodir doenças desconhecidas, de difícil tratamento, bem como reações biológicas inesperadas. Na realidade brasileira, todo esse conjunto fático aliado a um deficitário sistema de saúde pública configurou o que popularmente está a se chamar de "caos da saúde".

Neste viés, Carlos Antônio Bruno da Silva constata o que se tornou a saúde pública no Brasil, ao afirmar que nos "últimos 20 anos, tem havido uma progressiva deterioração do atendimento público, com queda de sua qualidade, tudo associado ao massacre de profissionais de saúde e pacientes submetidos à iniquidade econômica"40.

Destarte, resta claro que a sociedade passa por uma fase que, acima de tudo, exige cautela, conclama cuidados, a fim de que não se agrave a situação notoriamente de risco, tanto na seara ambiental como no âmbito da saúde.

Neste momento, avulta a prevenção em todas as suas perspectivas, inclusive as aqui protestadas, como um verdadeiro marco de sobrevivência, condição sine qua non de, até mesmo, continuidade humana, afigurando-se estruturalmente como um imperativo, algo que se impõe por si só como obrigatório, imperiosamente. Aliás, não apenas como simples imperativo se erige o princípio da prevenção, pois, por força de seu conteúdo, apresenta também natureza sociodemocrática.

Na esfera ambiental, quando se efetiva a prevenção, proporcionando a defesa do meio ambiente, irradiam-se efeitos para aqueles que ainda irão desfrutar do bem ambiental, para gerações que estão por vir, nos moldes do que dita o preceito constitucional insculpido no art. 225, particularmente quando se refere ao dever de preservar o meio ambiente ecologicamente equilibrado não apenas para as presentes, mas também para as futuras gerações.

Trata-se do princípio da solidariedade intergeracional, a consistir na relação entre gerações futuras e presentes, no sentido de preservar o meio ambiente, atuando de forma sustentável, a fim de que as próximas gerações possam continuar usufruindo dos recursos naturais. A solidariedade intergeracional,

39 Sampaio, 2003, p. 47.

40 Carlos Antonio Bruno da Silva, 2004, p. 2. 
consequência da ação preventiva, é um dos aspectos que, por exemplo, revela a face sociodemocrática desta.

Por ser o bem ambiental um bem de interesse difuso, repercutindo na esfera jurídica da coletividade, a atividade preventiva produz efeitos capazes de atingir uma pluralidade de pessoas, portadoras de suas individualidades, entretanto unidas pela situação de necessitarem do meio ambiente e de dele compartilharem, o que denota o caráter sociodemocrático assumido pelo princípio da prevenção.

No que concerne à saúde, como visto, a prevenção atua mitigando a proliferação de doenças nas populações, evitando eventos danosos à saúde das pessoas, repercutindo nas condições de vida de toda a sociedade, tendo em vista que, com os adventos da globalização e da interdependência funcional que assolam os aglomerados urbanos, permanece a sociedade intimamente ligada, o que a sensibiliza quando da afetação e repercussão de doenças.

Desta maneira, conclui-se que a saúde é aspecto que, por sua própria estrutura, exprime nuances de socialidade, de modo que o princípio da prevenção enseja uma atuação plural, abrangente, a gerar efeitos e produzir consequências práticas na vida de todos, ratificando a sua natureza sociodemocrática.

Portanto, revela-se a prevenção, em virtude da atual conjuntura social eivada de crises, como muito mais que mero aconselhamento ou orientação, mas sim, ao contrário, como nítido imperativo. Ademais, pelos efeitos que resultam de sua aplicação e por sua estrutura, tanto sob o enfoque ambiental como em face da saúde, a prevenção apresenta caráter sociodemocrático, ou seja, edifica-se na atualidade como verdadeiro imperativo sociodemocrático.

\section{CONCLUSÃO}

A evolução dos tempos fez eclodir problemas de difícil solução nas perspectivas sociais da atualidade, resultado de práticas humanas que prescindiram do planejamento necessário. Por consequência de políticas que, ao longo das épocas, não viam na prevenção o relevo que suscita, o meio ambiente e a saúde foram verdadeiramente comprometidos.

Em face da atual conjuntura social, a prevenção, a partir de sua natureza principiológica, representa grande diretriz a balizar as ações humanas, no sentido de evitar a ocorrência dos eventos danosos. Não se mostra razoável e nem se tem mais lastro para que se aguarde a ocorrência dos fatos lesivos, tanto na seara do ambiente como da saúde, principalmente pela fragilidade que estes campos hoje apresentam.

O direito ao meio ambiente ecologicamente equilibrado, prerrogativa de natureza difusa, encontra a sua grande afirmação nas linhas constitucionais, momento em que se constata a sua vital importância para o desenvolvimento 
humano. Neste sentido, urge salientar o papel crucial assumido pela prevenção, princípio que, a partir da certeza científica, constata a lesividade das condutas e determina todas as ações tendentes a evitá-la.

A seu turno, o direito à saúde, constitucionalmente assegurado a todos, encontra na prevenção um mecanismo fundamental para se efetivar, na medida em que as ações preventivas provocam a redução do aparecimento de doenças e as suas sequelas na sociedade, privilegiando o bem-estar coletivo.

Corolários do princípio da dignidade da pessoa humana, a defesa da saúde e a proteção do meio ambiente erigem-se como necessidades críticas da pós-modernidade. O reconhecimento de uma crise ambiental e a constatação do estado caótico no qual se encontra a saúde pública brasileira permitem entender a nova função de proeminência atribuída à prevenção.

Neste cenário, faz-se necessário imputar ao princípio em debate as vestes de imperativo sociodemocrático. A atuação preventiva não pode mais constituir-se como faculdade, ou até mesmo como mera orientação, pois não há mais espaço para que se perpetrem condutas agressivas tanto ao meio ambiente como à saúde.

Portanto, em virtude de tudo que foi exposto, cumpre ressalvar o relevo prático do princípio da prevenção na vida cotidiana. As consequências de um dano ambiental são incontáveis, aviltam a esfera de direitos de toda uma população, além de onerarem os cofres daqueles que pretendem repará-lo. Do mesmo modo, o advento de agravos à saúde minora as possibilidades de uma vida digna, a qual somente alcança a sua plenitude quando desfruta de um sistema de saúde que a atenda em todas as suas necessidades.

Neste jaez, a prevenção revela-se como um imperativo sociodemocrático, a evitar estes percalços, corroborando para uma existência plena e para um desenvolvimento humano completo.

\section{REFERÊNCIAS}

ALEXY, Robert; SILVA, Luis Virgilio Afonso da (Trad.). Teoria dos direitos fundamentais. São Paulo: Malheiros, 2008.

ANTUNES, Paulo de Bessa. Direito ambiental. 12. ed. Rio de Janeiro: Lumen Juris, 2010.

BONAVIDES, Paulo. Curso de direito constitucional. São Paulo: Malheiros, 2008.

BRASIL. Ministério do Meio Ambiente. Declaração do Rio sobre Meio Ambiente e Desenvolvimento. Disponível em: <http://www.mma.gov.br/port/sdi/ea/documentos/ convs/decl_rio92.pdf> Acesso em: 27 dez. 2012.

CANOTILHO, J. J. Gomes. Direito constitucional e teoria da constituição. 4. ed. Coimbra: Almedina, 1999. 
CZERESNIA, Dina. O conceito de saúde e a diferença entre prevenção e promoção. In: CZERESNIA, D.; FREITAS, C. M. (Org.). Promoção da saúde: conceitos, reflexões, tendências. Rio de Janeiro: Fiocruz, 2003.

DERANI, Cristiane. Direito ambiental econômico, São Paulo: Max Limonad, n. 25, 1997.

ELIAS, Alexandre Nemer. Direito sanitário: autonomia e princípios. Revista de Direito Sanitário, São Paulo, v. 9, n. 2, out. 2008. Disponível em: <http://www.revistasusp.sibi. usp.br/scielo.php?script=sci_arttext\&pid=S1516-41792008000200004\&lng=pt\&nrm=i so>. Acesso em: 20 dez. 2012.

FIORILlO, Celso Antonio Pacheco. Curso de direito ambiental brasileiro. 11. ed. São Paulo: Saraiva, 2010.

LAVIEILLE, Jean-Marc. Droit International de l'Environnment. Paris: Ellipses, 1998.

LEAVELL, S.; CLARCK, E. G. Medicina preventiva. São Paulo: McGraw-Hill, 1976.

LEITE, José Rubens Morato; AYALA, Patryck de Araújo. Dano ambiental: do individual ao coletivo extrapatrimonial. Teoria e prática. 4. ed. São Paulo: Revista dos Tribunais, 2011.

LÔBO, Marta Carolina Fahel. A tutela inibitória contra a Administração Pública na defesa do meio ambiente. In: KRELL, Andreas Joachim; MAIA, Alexandre da (Coord.). A aplicação do direito ambiental no estado federativo. 1. ed. Rio de Janeiro: Lumen Juris, 2005.

MACHADO, Paulo Affonso Leme. Direito ambiental brasileiro. 18. ed. rev., atual. e ampl. São Paulo: Malheiros, 2010.

MELLO, Celso Antônio Bandeira de. Curso de direito administrativo. 8. ed. São Paulo: Editores, 1996.

MILLARÉ, Édis. Direito do ambiente: a gestão ambiental em foco. 6. ed. rev., atual. e ampl. São Paulo: Revista dos Tribunais, 2009.

MIRANDA, Jorge. Manual de direito constitucional. Coimbra: Coimbra, t. 5, 1996.

MIRANDA, Pontes de. Comentários à Constituição de 1967. 1. ed. São Paulo: Revista dos Tribunais, t. I, 1967.

MUKAI, Toshio. Direito ambiental sistematizado. 3. ed. Rio de Janeiro: Forens, 1998.

RODRIGUES, Marcelo Abelha. Instituições de direito ambiental. Parte geral. São Paulo: Max Limonad, v. 1, 2002.

SAMPAIO, José Adércio Leite. Princípios de direito ambiental. Belo Horizonte: Del Rey, 2003.

SILVA, Carlos Antônio Bruno da. A saúde está um caos...? Revista Brasileira em Promoção da Saúde, Fortaleza, v. 17, n. 1, p. 1-2, 2004.

SILVA, José Afonso da. Direito ambiental constitucional. São Paulo: Malheiros, 2000.

SOARES NETTO, Francisco. Promoção da saúde e prevenção das doenças. São Paulo, 2011. Disponível em: <http://www.granclinic.com.br/artigos/promocao-da-saude-e-prevencao-das-doencas/>. Acesso em: 19 dez. 2012.

THOMÉ, Romeu. Manual de direito ambiental. Salvador: JusPodivm, 2011. 